\title{
Principal long-term adverse effects of imatinib in patients with chronic myeloid leukemia in chronic phase
}

This article was published in the following Dove Press journal:

Biologics: Targets \& Therapy

I December 2010

Number of times this article has been viewed

\author{
Tariq I Mughal ${ }^{1,2}$ \\ Andrew Schrieber' \\ 'University of Tennessee Medical \\ College, Memphis, Tennessee, USA; \\ 'Guy's and St Thomas' NHS Hospital, \\ Great Maze Pond, London, UK
}

\begin{abstract}
Imatinib mesylate (IM), an original Abl tyrosine kinase inhibitor, entered the clinics in 1998 for the treatment of patients with chronic myeloid leukemia (CML). The drug is universally considered the treatment of choice for most, if not all, patients with CML. Importantly, lessons learned from patients with CML have been applied successfully for the treatment of patients with other disorders where IM has since been found to be active by virtue of its ability to target other kinases, such as c-kit in patients with gastrointestinal stromal tumors. IM is associated with mild to moderate toxicity, mostly reversible by dose reduction or discontinuation of the drug. Most adverse effects occur within the first 2 years of starting therapy; however, late effects, many being unique, are now being recognized. In this report, we assess the toxicity associated with IM, with an emphasis on the long-term adverse effects.
\end{abstract}

Keywords: chronic myeloid leukemia, chronic phase, imatinib mesylate

\section{Introduction}

Imatinib mesylate (IM) (Gleevec ${ }^{\circledR}$, Novartis), a 2-phenylaminopyrimidine derivative, is a potent inhibitor of targeted protein tyrosine kinases, including BCR-ABL, c-kit, and platelet-derived growth factor receptor (PDGF-R), and was developed in the mid-1990s against a background of some uncertainty. ${ }^{1-3}$ The drug appears to work principally by occupying the ATP binding site of the BCR-ABL oncoprotein and thereby preventing phosphorylation of the substrate and interrupting contact with the effector protein. This results in abrogating the enzymatic function of the Bcr-Abl oncoprotein (Figure 1).

IM was first used in 1998 to treat patients with chronic myeloid leukemia (CML) in chronic phase (CP) resistant to interferon- $\alpha$, and early results showed that it was able to re-establish $\mathrm{Ph}$-negative (presumably normal) hematopoiesis in a proportion of these patients. ${ }^{4}$ This led to an international prospective clinical study (IRIS) in which newly diagnosed patients with CML in CP were randomly allocated to receive either IM at a dose of $400 \mathrm{mg}$ daily administered orally or a combination of interferon- $\alpha$ and cytarabine. The preliminary results were published in 2003 and updated periodically, the latest being in $2009 .{ }^{5-7}$ The results clearly demonstrated that nearly all patients achieved a complete hematologic response, with a significant proportion achieving a complete cytogenetic response (CCyR) and a minority achieving a complete molecular remission.

Although IM at a dose of $400 \mathrm{mg}$ daily yields excellent clinical results, higher doses (600-800 mg daily) have been shown to yield more rapid hematologic control and more rapid achievement of CCyR compared with the cohort receiving $400 \mathrm{mg} / \mathrm{day}$. The toxicity, however, associated with higher doses can sometimes be excessive
Guy's and St Thomas's NHS Hospital, Great Maze Pond, London SEI9RT, UK Email tmughal9II@hotmail.com 


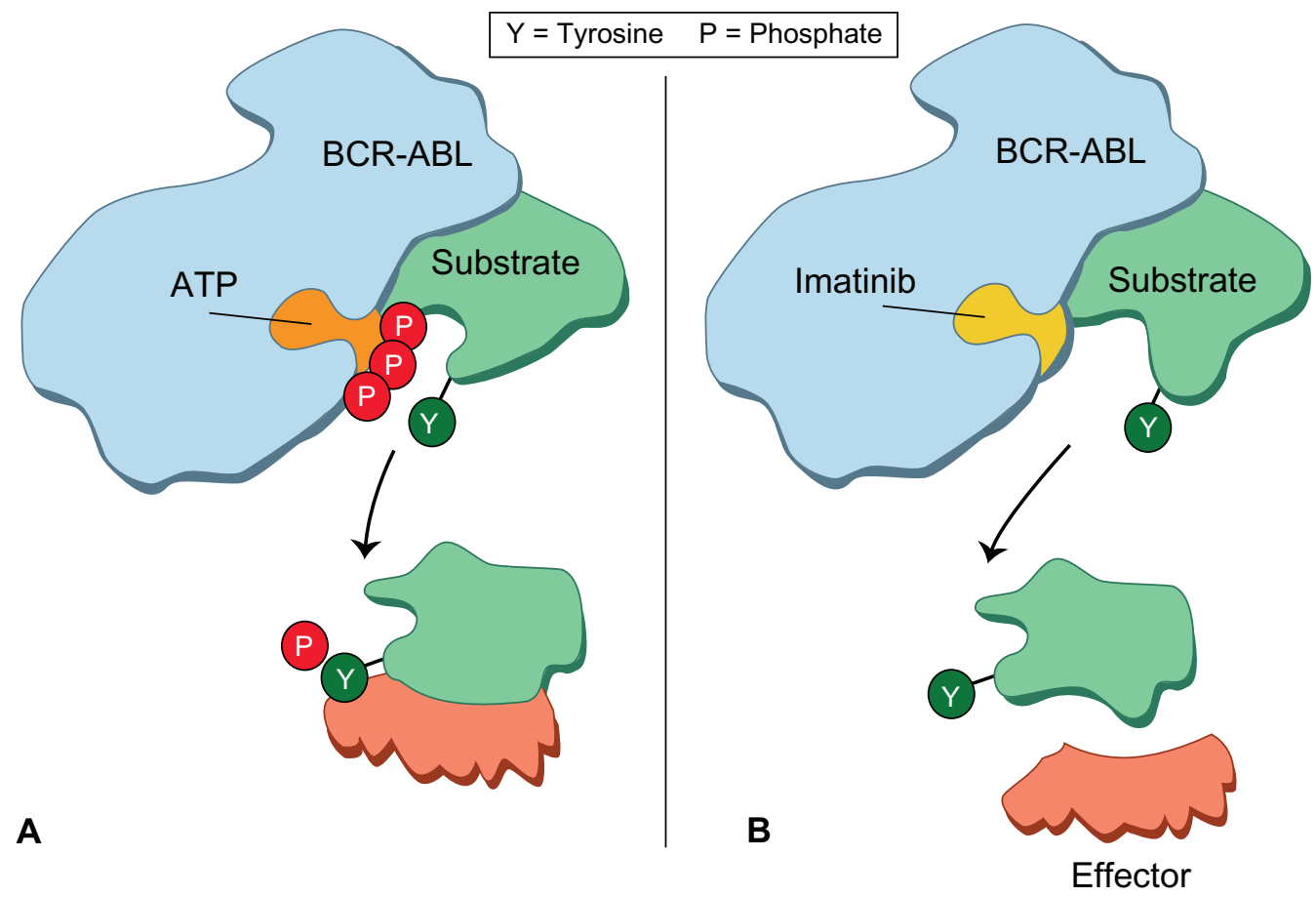

Figure I Mode of action of imatinib mesylate. The phosphorylation of a substrate is shown schematically. ATP occupies the pocket in the ABL component of BCR-ABL oncoprotein. The substrate then detaches itself from the BCR-ABL oncoprotein and makes functional contact with a further downstream effector molecule. When imatinib occupies the ATP binding site, it prevents phosphorylation of the substrate. This molecule in turn fails to make contact with the effector protein and the signal transduction pathway that would otherwise transmit the leukemia signal is interrupted. Reproduced with permission from Goldman and Mughal. ${ }^{70}$

resulting in frequent dose interruption and dose reduction. ${ }^{8,9}$ It is of interest that one of the recent studies confirmed this more rapid response with the higher dosage but suggested that by 18 months the short-term superiority had been lost. ${ }^{10}$ At present, it therefore seems reasonable to recommend that the best starting dose remains $400 \mathrm{mg}$ /day.

IM is associated with toxicity, though most of the adverse effects attributed occur within the first 2 years of starting therapy and some reverse with continued treatment at the same dose. Toxicity appears mild to moderate in most instances and appears easily manageable and potentially reversible. Some patients may experience lethargy and develop different types of rashes; others gain weight from fluid retention, especially infraorbital edema but occasionally much more generalized, which responds in some cases to diuretics. Other effects include bone pain, which can sometimes be debilitating. Liver chemistry can be abnormal, and this may, on rare occasions, progress to liver failure. Rare incidences of prolongation of the QTc interval on the electrocardiograph have been reported. A small proportion of patients in CP who start IM at $400 \mathrm{mg} /$ day experience cytopenias within the first year of therapy. They typically develop neutropenia and/or thrombocytopenia and sometimes anemia.
In general, all these side effects have been grade 1 or 2 and reversible on temporarily interrupting or stopping the drug. It is possible that some patients, for example older patients, and those with impaired cardiac function might perhaps be more susceptible to the adverse effects, particularly those which are long term. Herein, we assess the scenario with an emphasis on the long-term adverse effects associated with IM treatment for patients with CML in CP.

\section{Cardiac toxicity}

There has been much speculation pertaining to the potential cardiac toxicity associated with IM. One report suggested an increase risk of cardiac failure in patients taking IM for longer term, but subsequently extensive studies in different specialist centers from both sides of the Atlantic failed to substantiate this contention. ${ }^{711-14}$ This appears to be at variance to some of the other tyrosine kinase inhibitors (TKIs), such as sunitinib and sorafenib, where the risk associated with cardiac toxicity, compared with the general population in patients who have no evidence of a pre-existing cardiac problems, appears higher. ${ }^{15}$

In vitro preclinical studies conducted on human cardiomyocytes and murine models determined a possible pathway of cardiotoxicity involving the endoplasmic 
reticulum stress response and the effects of c-Abl inhibition. ${ }^{11}$ The investigators speculated that cardiac toxicity might be mediated by Jun N-terminal kinases leading to mitochondrial dysfunction and approximately a $65 \%$ decrease in available ATP. Park et al studied 16 patients with gastrointestinal stromal tumors (GIST), but not CML, and found elevated $\mathrm{N}$-terminal pro-B-type natriuretic peptide (BNP) levels in 2 patients who developed heart failure. ${ }^{16}$

The general consensus is that the majority of patients who develop cardiotoxicity, heart failure, and/or myocardial infarction are older ( $>65$ years old) and have pre-existing cardiac risk factors or existing cardiac disease. ${ }^{17,18}$ While overt clinical heart failure may well be of rare incidence in patients taking IM, studies to access early signs of heart failure have been undertaken. Measures of cardiac function via laboratory findings were evaluated to detect the early onset of cardiotoxicity. Perik et al followed N-terminal pro-BNP and serum cardiac troponin $\mathrm{T}$ for 9 months in 55 patients with GIST on IM to determine if IM caused subclinical cardiotoxicity. ${ }^{19}$ Two patients developed elevated levels, one with existing heart failure and the other with a history of heart failure due to mitral valve regurgitation. Also, Tiribelli et al reported similar results following N-terminal pro-BNP levels in 49 patients with CML. ${ }^{20}$

Other cardiac adverse effects include pericarditis, tachycardia, hypertension, and hypotension and collectively the incidence appears less than $1.0 \%$. It seems reasonable to state that, based on currently available evidence, cardiac toxicity does not appear to be a significant risk factor of long-term IM therapy. It will, however, appear prudent to remain vigilant. Clearly, patients with a pre-existing cardiac problem should be observed very closely and if signs of cardiac dysfunction develop, alternative treatment should be considered.

\section{Abnormal bone and mineral metabolism}

Many efforts have been made to study the effect of IM on bone and mineral metabolism. A principal study was conducted by Berman et al. ${ }^{21}$ They assessed patients on IM for either GIST or CML and noted that hypophosphatemia with associated bone and mineral metabolic changes developed in a significant number of patients. The authors hypothesized that abnormalities in bone and mineral metabolism may be secondary to hypophosphatemia, but also as a direct result of inhibiting the PDGF-R. There is some support for this notion from observations in cultured osteoprogenitor and osteoblasts from fetal rats, for which PDGF-R $\alpha$ gene was found to be present. ${ }^{22}$ Also replication and migration of rat osteoblasts secondary to PDGR-AA and PDGF-BB has been shown. ${ }^{23,24}$ It has also been suggested using prospectively collected data that altered bone remodeling and secondary hyperparathyroidism apparently occur in the early stages of IM therapy. ${ }^{25}$ It has been postulated that IM directly stimulates osteoblast bone building activity and limits osteoclast bone resorption activity (Figure 2), resulting in a net flux of calcium from extracellular fluid into bone, a decreased serum calcium level, and a compensatory rise in the level of parathyroid hormone, thus leading to phosphaturia and hypophosphatemia. ${ }^{26}$ More recently, human bone marrow mesenchymal stem cells (hBM-MSCs) were evaluated to determine their response to imatinib. ${ }^{27}$ After 21 days of culture, hBM-MSCs treated with IM showed morphological alteration, with increased extracellular mineralization and mRNA expression of osteogenic markers, such as RUNX2, osteocalcin, and bone morphogenetic protein-2. ${ }^{27}$ These data suggested that IM potentially favors osteoblastogenesis.

The longer term effects of IM therapy on bone remodeling have also been studied. Fitter et al evaluated the effect of long-term therapy on osteoblastic function in an attempt to evaluate the effects of IM on skeletal metabolism. ${ }^{28}$ This was done by performing a pre- and (2-4 year) post-treatment analysis on patients' bone marrow. The authors observed an increase in total bone volume along with a significant decrease in serum phosphate and calcium concentrations after extended IM therapy. They speculated that IM restrains bone resorption (by inhibiting c-Fms on osteoclasts) and stimulates bone formation (by inhibiting PDGF-R on osteoblasts), thus sequestrating both calcium and phosphate in bone. This can result in secondary hyperparathyroidism, which decreases renal phosphate absorption, leading to hypophosphatemia.

The clinical implications of the above studies are limited at the current time. While it appears that monitoring phosphorous and vitamin D levels may be reasonable, further studies are desirable, particularly to determine the long-term effects. The Société Française des Cancers de l'enfant (SFCE) recently reported the results of an open-label, multicentric phase IV trial assessing the efficacy and safety of IM in children and adolescents with untreated CML and confirmed a significant decrease of height in 22 of the 44 study patients. ${ }^{29}$ This negative impact of IM on skeletal growth also merits further study.

\section{Pregnancy}

Since IM first entered the clinics almost a decade ago, for the management of patients with CML, there have been a number of ad hoc observations and reports suggesting the potential 


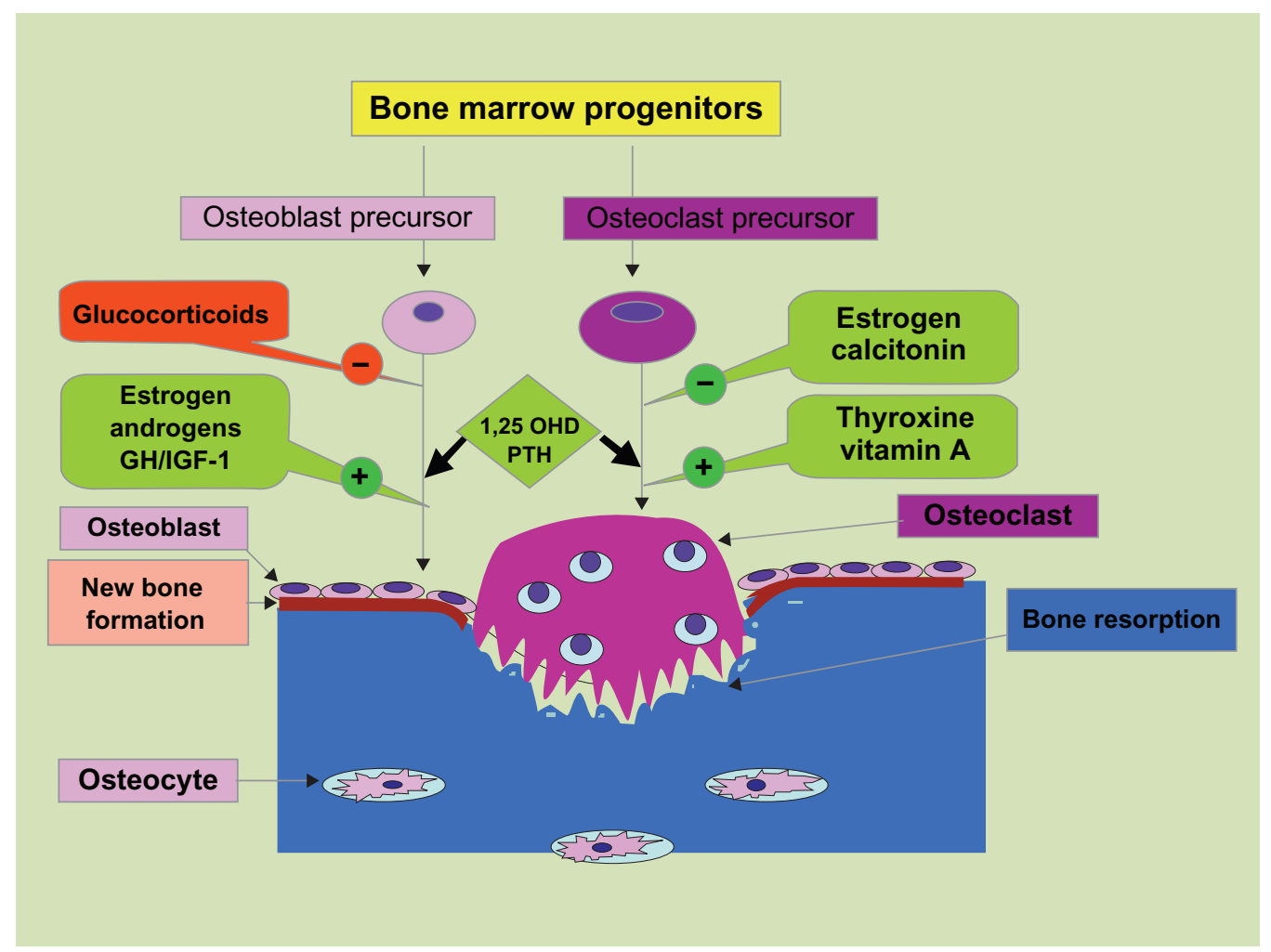

Figure 2 Development of osteoblasts and osteoclasts from bone marrow progenitors. Factors affecting the development and function of these cells, bone resorption by osteoclast, and new bone formation by osteoblasts. Copyright (C) 2006. Reproduced with permission from Valsamis et al; licensee BioMed Central Ltd. Alsamis HA, et al. Antiepileptic drugs and bone metabolism. Nutr Metab. 2006;3:36. doi:10.1 186/1743-7075-3-36.71

Abbreviations: GH, growth hormone; IGF, insulin-like growth factors; PTH, parathyroid hormone.

detrimental effect of IM on the outcomes of pregnancy when either partner has been exposed to the drug. In preclinical data, mice were noted to have numerous teratogenic effects including perinatal mortality; abnormal spleen, head, and eye development; and abnormal immune system function. ${ }^{30}$ This has been speculated to be possibly related to the loss of Abl for a proper embryonic development. Based on such preclinical data, the manufacture of IM (Novartis) issued strict recommendations for female patients of child-bearing age, stating avoidance of IM when attempting to become or becoming pregnant.
A small study from Houston in 2006 described outcomes of pregnancies in 19 patients undergoing treatment with IM. It is of interest that this study assessed 10 females and 8 males whose partners were pregnant. ${ }^{31} \mathrm{IM}$ therapy was discontinued in all female patients immediately following the confirmation of pregnancy. The majority of patients conceived without complication, and the authors concluded that conception among patients with CML receiving IM can ultimately lead to normal pregnancies, but given the low number of patients, an effect on miscarriages and birth abnormalities could not be ruled out.

Table I Most frequently reported adverse effects in patients with CML in CP treated with imatinib

\begin{tabular}{|c|c|c|}
\hline $\begin{array}{l}\text { Most common adverse } \\
\text { effects (by } 5 \text { years) }\end{array}$ & $\begin{array}{l}\text { All grades of adverse } \\
\text { effects in patients (\%) }\end{array}$ & $\begin{array}{l}\text { Grade } 3 / 4 \text { adverse effects } \\
\text { in patients (\%) }\end{array}$ \\
\hline Superficial edema & 60 & 2 \\
\hline Nausea & 50 & I \\
\hline Muscle cramps & 49 & 2 \\
\hline Musculoskeletal pain & 47 & 5 \\
\hline Diarrhea & 45 & 3 \\
\hline Rash/skin problems & 40 & 3 \\
\hline Fatigue & 39 & 2 \\
\hline Headache & 37 & $<1$ \\
\hline Abdominal pain & 37 & 4 \\
\hline Joint pain & 31 & 3 \\
\hline
\end{tabular}

Note: Only serious adverse effects were collected after 2005; grade 3/4 adverse effects decreased in incidence after years I-2. Abbreviations: CML, chronic myeloid leukemia; CP, chronic phase. 
A much larger international retrospective study of 180 female patients exposed to IM during pregnancy was published in 2008, with the timing of exposure available in 146 of 180 patients. ${ }^{32}$ Exposure to IM occurred in 103 of 146 patients during the first trimester; 38 of 146 patients received the drug throughout their pregnancy. Data on the outcome of pregnancy were available for 125 of $180(69 \%)$ patients. Half of these patients ( 63 of $125 ; 35 \%$ of all pregnant patients) gave birth to normal live infants; 35 (28\%) patients elected to have the pregnancy terminated, including 3 who were identified to have fetal abnormalities; and 18 (14.4\%) patients had a spontaneous abortion. Of the remaining 9 of 125 pregnancies, there were 8 live births and 1 stillbirth, all with congenital abnormalities. In sum, therefore, there were 12 infants with congenital abnormalities in this series of patients, including 3 with a combination of similar skeletal abnormalities, including deformities of skull bones. The authors felt that the incidence of these abnormalities was in excess of the reported incidence in general population and were probably related to IM exposure.

It is, therefore, prudent to advise female patients to avoid conception while on IM. The management of women who do conceive while on IM is enigmatic, with some specialists advocating a fine balance of the risks to both the mother and the fetus versus the potential for a loss of response on discontinuing IM (Table 2). Parenthetically, it should be noted that since IM is secreted in breast milk, breastfeeding is not recommended while on IM.

Current evidence does not suggest a congenital risk in male patients who are on IM at time of their partner conceiving, but it would appear reasonable to remain cautious. Oligospermia and reduced sperm motility have been observed in animals and humans treated with IM. ${ }^{33}$ A potential option might be to cryopreserve sperms prior to starting therapy with IM..$^{34}$

Table 2 Imatinib and reproduction: suggested recommendations to providers for patients taking imatinib by gender

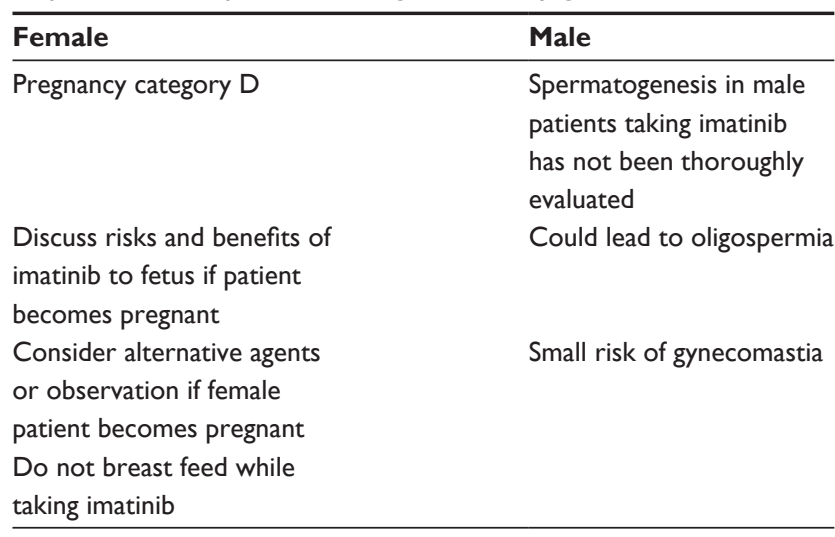

\section{Gynecomastia}

It has been shown that both c-kit and PDGF-R are expressed in the male testis. IM can decrease testosterone production by the inhibition of these receptors..$^{35}$ Decreased testosterone production over time can lead to gynecomastia, which has been noted with long-term IM exposure and is possibly secondary to inhibition of c-kit and PDGF-R. Gambacorti-Passerini et al evaluated hormone levels and clinical evidence of gynecomastia in 38 patients at baseline and on treatment with imatinib. ${ }^{35}$ In the majority of patients studied, IM was associated with a decrease in the production of testicular hormones, and in 7 patients gynecomastia was noted. Gynecomastia has also been reported in a patient on IM for GIST. ${ }^{36}$

\section{Hypothyroidism}

Current evidence suggests an association between some TKIs, such as sunitinib and sorafenib, but not IM, and hypothyroidism. ${ }^{37-39} \mathrm{IM}$, however, can affect patients treated with levothyroxine for hypothyroidism. de Groot et al described a cohort of 11 patients (10 with medullary thyroid carcinoma and 1 with GIST) treated with IM and levothyroxine concurrently. ${ }^{40}$ Thyroid function was evaluated before, during, and 2 weeks after therapy with IM or after levothyroxine was discontinued. Symptomatic hypothyroidism was noted in all patients who previously underwent thyroidectomy but was not present in those who did not undergo surgery. Patients who had undergone thyroidectomy had markedly elevated thyroid-stimulating hormone (TSH) levels and required an increase of levothyroxine during IM dosing. TSH decreased after discontinuing treatment, which suggested that IM might be the causative agent. ${ }^{40}$ The authors suggested that non-deiodination clearance was the most likely mechanism responsible for IM-induced hypothyroidism in patients who receive replacement therapy.

At present it appears reasonable to monitor TSH levels more frequently in IM-treated patients on thyroid replacement. Moreover, based on the findings of overt hypothyroidism secondary to the use of other TKIs, it would also be prudent to monitor thyroid function in patients who exhibit symptoms of hypothyroidism.

\section{Immune function}

In view of the several off-target kinases that IM and other TKIs inhibit, such as c-kit and PDGF-R, which play a normal physiological role in immune responses, it has been speculated that these drugs will probably have an impact on the immune responses of patients. Recently, investigators have reported a range of effects, from hypogammaglobulinemia 
to a suppressive effect on $\mathrm{T}$ - and NK-cell activation and cytotoxicity in vitro. ${ }^{41}$ While hypogammaglobulinemia is typically associated with chronic lymphocytic leukemia, it is uncommon in untreated CML. Santachiara et al reported significant hypogammaglobulinemia in about $10 \%$ of an 87-patient study group treated with IM for CML or GIST. ${ }^{42}$ It is also of interest that ad hoc reports suggest the presence of uncommon opportunistic infections, including peritoneal tuberculosis and atypical candida pneumonia, in patients on IM who were not neutropenic or had clinical signs of immunosuppression. ${ }^{43}$

There are also reports supporting the notion that the immune effects mediated by IM might be global, with impairment of the function of human regulatory T cells (Tregs) and antigen presenting cells. ${ }^{44} \mathrm{IM}$ has also been speculated to reverse the inhibition of immune responses to IM-resistant CML cells by Tregs.

\section{Cutaneous toxicity}

Cutaneous reactions are probably TKI-class related and often seen in patients with CML on IM. The precise incidence of rashes appears to be around $35 \%$, with most associated with pruritus. ${ }^{45}$ It is not entirely clear if these are dose related or not; the prevalence appears to be maximum in the early stages of IM treatment. Severe life-threatening exfoliative dermatitis and Stevens-Johnsons syndrome have also been reported on rare occasions and have generally occurred within 10 days of starting therapy. ${ }^{46}$ In most, if not all, cases the rash and pruritus subside significantly with treatment interruption alone; on some occasions, the addition of a short course of steroids is helpful. ${ }^{47-49}$

Though long-term rashes are less common, it is not uncommon to witness intermittent reappearance of rash and pruritus, particularly if the dose of IM is escalated. ${ }^{50,51}$ Other forms of cutaneous toxicity associated with IM is skin hyper/hypopigmentation, which appears to persist even when IM is discontinued. Hypopigmentation, perhaps related to inhibition of c-kit, may or may not be associated with rash and is more prevalent in ethnically pigmented patients. ${ }^{52-54}$ It is of considerable interest that IM has also been associated with repigmentation of gray hair. In a study of 133 patients with CML on IM, 8 patients noted progressive repigmentation of scalp gray hair. ${ }^{55}$ Whereas hyperpigmentation of skin and hair is more commonly seen in patients with fair complexions, other toxicities, such as dry skin, pruritus, and photosensitivity present in all patients, often early, and may persist throughout therapy. ${ }^{56}$

\section{Hepatotoxicity}

About $5 \%$ of all patients with CML appear to develop mild (grade 1/2) hepatotoxicity characterized by an abnormal bilirubin and transaminases within the first 2 years of receiving IM. Serious hepatotoxicity (grade 3/4) is, however, extremely rare. ${ }^{4}$ In all cases, the hepatic dysfunction appears to be fully reversible with dose interruption/dose reduction. Talpaz et al reported a patient on IM who developed severe hepatic failure and died while receiving concurrent acetaminophen. ${ }^{58}$ Other case reports of fatal hepatic failure related to IM pertain to a patient with myelofibrosis/polycythemia vera who received IM at $400 \mathrm{mg} /$ day, and a patient who had a liver transplant for the treatment of suspected imatinib-induced acute liver failure. ${ }^{57,58}$

It is, therefore, prudent to monitor hepatic function frequently, perhaps once weekly to commence and thereafter about once a month. In patients who experience grade 3-4 hepatotoxicity, it is appropriate to discontinue IM and reintroduce treatment cautiously once the liver chemistry has normalized. Some specialists advocate the use of steroids, and indeed reports of a regression of hepatotoxicity and allowing imatinib therapy to be continued have been documented. ${ }^{59,60}$

\section{Pulmonary toxicity}

Pulmonary toxicity causally related to IM therapy is uncommon. Ohnishi et al collated data from 27 patients who appeared to have developed interstitial lung disease (ILD) while on IM therapy. ${ }^{61}$ The majority of these patients (23 of 27) either improved or had complete resolution of ILD with the discontinuation of IM and the addition of low doses of short-term steroids. Due to the very rare occurrence of this side effect, there is no firm consensus with regard to its optimal management. It is probably reasonable to withhold IM therapy until the pulmonary functions recover and consider alternative therapy thereafter.

\section{Secondary malignancies}

There has been considerable interest with regard to the potential for TKIs to result in secondary malignancies, particularly in regards to myeloid malignancies. This stemmed largely from observations made in a small cohort of patients with CML receiving IM who developed diverse chromosomal abnormalities in the Ph-negative metaphases as they achieved major or CCyR. ${ }^{62-66}$ Initially, it was speculated that these findings were transient and probably not sinister, but of unknown clinical consequences. Thereafter, multiple reports appeared pertaining to patients with CML with chromosomal 
Table 3 Incidence of notable short- and long-term reported toxicities of imatinib

\begin{tabular}{llll}
\hline Percentage & $>\mathbf{I 0} \%$ & $\mathbf{I} \%-\mathbf{I 0 \%}$ & $<\mathbf{I . 0 \%}$ \\
\hline Short-term toxicities & $\begin{array}{l}\text { Superficial edema, muscle cramps, } \\
\text { nausea, musculoskeletal pain, } \\
\text { diarrhea, rash, fatigue, headache, } \\
\text { abdominal pain, joint pain }\end{array}$ & $\begin{array}{l}\text { Pancytopenia, febrile } \\
\text { neutropenia, flushing, } \\
\text { liver function test } \\
\text { abnormalities }\end{array}$ & Pleural effusion, syncope, angioedema \\
Long-term toxicities & NA & NA & Cardiac toxicities, secondary malignancy, myositis, \\
& & & $\begin{array}{l}\text { multiple sclerosis, renal failure, dermatitis } \\
\text { pancreatitis, hypophosphatemia, gynecomastia, } \\
\text { hypogammaglobulinemia, opportunistic infections, } \\
\text { hepatotoxicities, pulmonary toxicities, skin } \\
\text { hyper/hypopigmentation, cerebral edema }\end{array}$ \\
\hline
\end{tabular}

Abbreviation: NA, not applicable.

abnormalities in the Ph-negative metaphases treated with IM alone or in combination with other agents who go on to develop myelodysplastic syndrome/acute myelogenous leukemia (MDS/AML). Kovitz et al analyzed 1,701 patients and reported 3 patients treated with IM for CML who subsequently developed AML $(n=1)$ and high-risk $\operatorname{MDS}(n=2) .{ }^{67}$ In a further series from the MD Anderson Hospital in Texas involving 258 patients with newly diagnosed CML treated with first-line IM, at median follow-up of 37 months, chromosomal abnormalities in $\mathrm{Ph}$-negative metaphases occurred in $9 \%$ of patients. ${ }^{68}$ These investigators also noted a patient with monosomy 7 , who developed AML, but no evidence of dysplasia or acute leukemia was seen in any other patients.

It has been hypothesized that these effects were probably not solely secondary to IM since these changes have not been reported in diseases other than CML treated with IM, and they occur in patient with CML treated with alternative drugs, including interferon. Regardless, it is useful to monitor patients on IM with bone marrow aspirations and cytogenetic analysis if a secondary clonal event is suspected. The emergence of Ph-negative metaphase chromosomal abnormalities in this scenario is not necessarily an absolute indication to change the treatment strategy per se unless additional complications (trilineage dysplasia) arise.

With regard to nonmyeloid malignancies, there was much speculation of the possible increase in the risk of urothelial malignancies in a small cohort of patients subjected to imatinib. ${ }^{61}$ Importantly, however, a much larger study of 9,000 patients failed to confirm this suspicion. ${ }^{62}$

\section{Conclusion}

Long-term side effects of IM are now being well documented and appear rare. Table 3 shows the incidence of long-term adverse effects compared with the acute adverse effects. It is likely that as ongoing follow-up of earlier studies that have basically evolved into longitudinal studies continues, additional long-term complications and increased incidence of current known complications may be noted. It is recommended that specialists remain cautious about the potential long-term adverse effects associated with IM. Some specialists have observed rare but potential sinister effects: Ebnöether et al noted the potentially lethal toxicity of cerebellar edema in 2 separate patients, but this has not been noted in other cases in the literature or in extended follow-up. ${ }^{69}$ In addition, other possibly significant long-term complications noted from case reports and small retrospective reviews, including optic effects and sensorineural hearing loss, have been noted but are not prominent in any of the larger studies or retrospective reviews.

The above findings highlight some of the issues evaluating the long-term toxicities of a drug that is in its relative infancy. Some findings that may be present in the preclinical setting are not always evident in the clinical setting, and vice versa. While case reports and retrospective reviews are an integral part of clinical practice, there can be many confounding variables that lead to adverse toxicities that in fact may not be secondary to the suspected offending agent. Importantly, it would appear that following a decade since IM entered the clinics, the safety analysis suggests that the long-term adverse effects are quite acceptable.

\section{Disclosure}

The authors report no conflicts of interest in this work.

\section{References}

1. Buchdunger E, Zimmermann J, Mett $\mathrm{H}$, et al. Selective inhibition of the platelet-derived growth factor signal transduction pathway by a proteintyrosine kinase inhibitor of the 2-phenylaminopyrimidine class. Proc Natl Acad Sci U S A. 1995;92:2558-2562.

2. Druker BJ, Tamura S, Buchdunger E, et al. Effects of a selective inhibitor of the ABL tyrosine kinase on the growth of BCR-ABL positive cells. Nat Med. 1996;2:561-566.

3. Heinrich MC, Griffith DJ, Druker BJ, et al. Inhibition of c-kit receptor tyrosine kinase activity by STI 571 , a selective tyrosine kinase inhibitor. Blood. 2000;96:925-932. 
4. Deininger MW, O’Brien SG, Ford JM, Druker BJ. Practical management of patients with chronic myeloid leukemia receiving imatinib. $J$ Clin Oncol. 2003;21:1637-1647.

5. Druker BJ, Guilhot F, O'Brien SG, et al. Five-year follow-up of imatinib therapy for chronic-phase chronic myeloid leukemia. $N$ Engl J Med. 2006;355:2408-2417.

6. Mughal TI, Goldman JM. Optimal management of patients with newly diagnosed chronic phase chronic myeloid leukemia in 2007. Clin Lymphoma Myeloma. 2007;7:338-339.

7. Hochhaus A, O’Brien SG, Guilhot F, et al. Six year follow-up of patients receiving imatinib for the first-line treatment of chronic myeloid leukemia. Leukemia. 2009;213:1054-1061.

8. Kantarjian H, Talpaz M, O’Brien S, et al. High dose imatinib mesylate therapy in newly diagnosed Philadelphia chromosome-positive chronic myeloid leukemia. Blood. 2004;103:2873-2878.

9. Hughes TP, Branford S, White DL, et al. Impact of early dose intensity on cytogenetic and molecular responses in chronic-phase CML patients receiving $600 \mathrm{mg} /$ day of imatinib as initial therapy. Blood. 2008;112:3965-3973.

10. Cortes JE, Baccarani M, Guilhot F, et al. Phase III. Randomized, open-label study of daily imatinib mesylate $400 \mathrm{mg}$ versus $800 \mathrm{mg}$ in patients with newly diagnosed, previously untreated chronic myeloid leukemia in chronic phase using molecular end points: tyrosine kinase inhibitor optimization and selectivity study. J Clin Oncol. 2010;28: 424-430.

11. Kerkela R, Grazette L, Yacobi R, et al. Cardiotoxicity of the cancer therapeutic agent imatinib mesylate. Nat Med. 2006;12:908-916.

12. Schiffer CA. BCR-ABL tyrosine kinase inhibitors for chronic myelogenous leukemia. N Engl J Med. 2007;357:258-265.

13. Atallah E, Kantarjian H, Cortes J. In reply to 'Cardiotoxicity of the cancer therapeutic agent imatinib mesylate’. Nat Med. 2007;13:14; author reply $15-16$.

14. Rosti G, Martinelli G, Baccarani M. In reply to 'Cardiotoxicity of the cancer therapeutic agent imatinib mesylate'. Nat Med. 2007;13:15; author reply $15-16$.

15. Schmidinger M, Zielinski CC, Vogl UM, et al. Cardiac toxicity of sunitinib and sorafenib in patients with metastatic renal cell carcinoma. $J$ Clin Oncol. 2008;26:5204-5212.

16. Park YH, Park HJ, Kim BS, et al. BNP as a marker of the heart failure in the treatment of imatinib mesylate. Cancer Lett. 2006;243:16-22.

17. Atallah E, Durand JB, Kantarjian H, Cortes J. Congestive heart failure is a rare event in patients receiving imatinib therapy. Blood. 2007;110:1233-1237.

18. Ribeiro AL, Marcolino MS, Bittencourt HN, et al. An evaluation of the cardiotoxicity of imatinib mesylate. Leuk Res. 2008;32:1809-1814.

19. Perik PJ, Rikhof B, de Jong FA, et al. Results of plasma N-terminal pro B-type natriuretic peptide and cardiac troponin monitoring in GIST patients do not support the existence of imatinib-induced cardiotoxicity. Ann Oncol. 2008;19:359-361.

20. Tiribelli M, Colatutto A, Marin L, et al. Brain natriuretic peptide level as marker of cardiac function in imatinib-treated chronic myeloid leukemia patients: no evidence of cardiotoxicity of imatinib therapy. Am J Hematol. 2008;83:517-518.

21. Berman E, Nicolaides M, Maki RG, et al. Altered bone and mineral metabolism in patients receiving imatinib mesylate. $N$ Engl J Med. 2006;354:2006-2013.

22. Liu F, Malaval L, Aubin JE. Global amplification polymerase chain reaction reveals novel transitional stages during osteoprogenitor differentiation. J Cell Sci. 2003;116:1787-1796.

23. Hock JM, Canalis E. Platelet-derived growth factor enhances bone cell replication, but not differentiated function of osteoblasts. Endocrinology. 1994;134:1423-1428.

24. Fiedler J, Etzel N, Brenner RE. To go or not to go: migration of human mesenchymal progenitor cells stimulated by isoforms of PDGF. J Cell Biochem. 2004;93:990-998.
25. Grey A, O'Sullivan S, Reid IR, Browett P. Imatinib mesylate, increased bone formation, and secondary hyperparathyroidism. $N$ Engl J Med. 2006;355:2494-2495.

26. O'Sullivan S, Horne A, Wattie D, et al. Decreased bone turnover despite persistent secondary hyperparathyroidism during prolonged treatment with imatinib. J Clin Endocrinol Metab. 2009;94:1131-1136

27. Tibullo D, Giallongo C, La Cava P, et al. Effects of imatinib mesylate in osteoblastogenesis. Exp Hematol. 2009;37:461-468.

28. Fitter S, Dewar AL, Kostakis P, et al. Long-term imatinib therapy promotes bone formation in CML patients. Blood. 2008;111:2538-2547.

29. Frédéric M, Baruchel A, Guilhot J, et al. Imatinib is efficient but has a negative impact on growth in children with previously untreated chronic myelogenous leukemia (CNL) in early chronic phase (CP): results of the French National Phase IV trial. ASH proceedings; 2009; [Abstract 863].

30. Schwartzberg PL, Stall AM, Hardin JD, et al. Mice homozygous for the ablm 1 mutation show poor viability and depletion of selected $B$ and T cell populations. Cell. 1991;65:1165-1175.

31. Ault P, Kantarjian H, O'Brien S, et al. Pregnancy among patients with chronic myeloid leukemia treated with imatinib. J Clin Oncol. 2006;24:1204-1208.

32. Pye SM, Cortes J, Ault P, et al. The effects of imatinib on pregnancy outcome. Blood. 2008;111:5505-5508.

33. Seymour JF, Grigg A, Reynolds J, et al. Two year data from a prospective safety study analyzing the consequences of imatinib mesylate inhibition of sensitive kinases other than bcr-abl in patients with previously untreated chronic phase CML [abstract]. Blood. 2006;108:2147a.

34. Martin H, Heiko van der Kuip, Walter EA. Therapeutic options for chronic myeloid leukemia: focus on imatinib. Ther Clin Risk Manag. 2008;4:163-187.

35. Gambacorti-Passerini C, Tornaghi L, Cavagnini F, et al. Gynaecomastia in men with chronic myeloid leukaemia after imatinib. Lancet. 2003;361:1954-1956.

36. Hawk K, Heung-Moon C, Min-Hee R, Tae-Won K, Hee-Jung S, So-Eun K. Concurrent male gynecomastia and testicular hydrocele after imatinibmesylate treatment of a gastrointestinal stromal tumor. $J$ Korean Med Sci. 2005;20:512-515.

37. Mannavola D, Coco P, Vannucchi G, et al. A novel tyrosine kinase inhibitor, sunitinib, induces transient hypothyroidism by blocking iodine uptake. J Clin Endocrinol Metab. 2007;92:3531-3534.

38. Tamaskar I, Bukowski R, Elson P, et al. Thyroid function test abnormalities in patients with metastatic renal cell carcinoma treated with sorafenib. Ann Oncol. 2008;19:265-268.

39. Torino F, Corsello S. Longo R, et al. Hupothyroidism related to tyrsoine kinase inhibitors: an emerging toxic effect on targeted therapy. Nat Rev Clin Oncol. 2009;6:219-228.

40. de Groot JW, Zonnenberg BA, Plukker JT, van Der Graaf WT, Links TP. Imatinib induces hypothyroidism in patients receiving levothyroxine. Clin Pharmacol Ther. 2005;78:433-438.

41. Mustjoki S, Ekblom M, Arstila TP, et al. Clonal expansion of T/NK-cells during tyrosine kinase inhibitor dasatinib therapy. Leukemia. 2009;23:1398-1405.

42. Santachiara R, Maffei R, Martinelli S, et al. Development of hypogammaglobulinemia in patients treated with imatinib for chronic myeloid leukemia or gastrointestinal stromal tumor. Haematologica. 2008;93:1252-1255.

43. Senn L, Kovacsovics T, Tarr PE, Meylan P. Peritoneal tuberculosis after imatinib therapy. Arch Intern Med. 2009;169:312-313.

44. Ogasawara M, Matsukawa T, Katsura Y. Imatinib impairs the function of human regulatory $\mathrm{T}$ cells (Tregs) and reverses the inhibition of immune responses to imatinib-resistant CML cells by Tregs. ASH Meeting Proceedings; 2009 Dec; 1114:4728. 
45. Van Glabbeke M, Verweij J, Casali PG, et al. Predicting toxicities for patients with advanced gastrointestinal stromal tumours treated with imatinib: a study of the European Organisation for Research and Treatment of Cancer, the Italian Sarcoma Group, and the Australasian Gastro-Intestinal Trials Group (EORTC-ISG-AGITG). Eur J Cancer. 2006;42:2277-2285

46. Larson RA, Druker BJ, Guilhot F, et al. Imatinib pharmacokinetics and its correlation with response and safety in chronic-phase chronic myeloid leukemia: a subanalysis of the IRIS study. Blood 2008;111:4022-4028.

47. Brouard M, Saurat JH. Cutaneous reactions to STI571. N Engl J Med. 2001;345:618-619.

48. Hsiao LT, Chung HM, Lin JT, et al. Stevens-Johnson syndrome after treatment with STI571: a case report. Br J Haematol. 2002;117: 620-622.

49. Nelson RP Jr, Cornetta K, Ward KE, et al. Desensitization to imatinib in patients with leukemia. Ann Allergy Asthma Immunol. 2006;97:216-222.

50. Park MA, Volcheck GW, Guarderas JC. Successful progressive challenge after a cutaneous reaction to imatinib mesylate (Gleevec): a case report and review of the literature. Allergy Asthma Proc. 2004;25:345-347.

51. Rule SA, O’Brien SG, Crossman LC. Managing cutaneous reactions to imatinib therapy. Blood. 2002;100:3434-3435.

52. Gambillara E, Laffitte E, Widmer N, et al. Severe pustular eruption associated with imatinib and voriconazole in a patient with chronic myeloid leukemia. Dermatology. 2005;211:363-365.

53. Severino G, Chillotti C, De Lisa R, et al. Adverse reactions during imatinib and lansoprazole treatment in gastrointestinal stromal tumors. Ann Pharmacother. 2005;39:162-164.

54. Raanani P, Goldman JM, Ben-Bassat I. Challenges in oncology. Case 3. Depigmentation in a chronic myeloid leukemia patient treated with STI-571. J Clin Oncol. 2002;20:869-870.

55. Valeyrie L, Bastuji-Garin S, Revuz J, et al. Adverse cutaneous reactions to imatinib (STI571) in Philadelphia chromosome-positive leukemias: a prospective study of 54 patients. J Am Acad Dermatol. 2003;48:201-206.

56. Arora B, Kumar L, Sharma A, et al. Pigmentary changes in chronic myeloid leukemia patients treated with imatinib mesylate. Ann Oncol. 2004; 15:358-359.

57. Etienne G, Cony-Makhoul P, Mahon FX. Imatinib mesylate and gray hair. N Engl J Med. 2002;347:446-447.

58. Talpaz M, Silver RT, Druker BJ, et al. Imatinib induces durable hematologic and cytogenetic responses in patients with accelerated phase chronic myeloid leukemia: results of a phase 2 study. Blood. 2002;99:1928-1937.
59. Lin NU, Sarantopoulos S, Stone JR, et al. Fatal hepatic necrosis following imatinib mesylate therapy. Blood. 2003;102: 3455-3456.

60. Ferrero D, Pogliani EM, Rege-Cambrin G. Corticosteroids can reverse severe imatinib-induced hepatotoxicity. Haematologica. 2006;91:35-37.

61. Ohnishi K, Sakai F, Kudoh S, et al. Twenty-seven cases of drug-induced interstitial lung disease associated with imatinib mesylate. Leukemia. 2006;20:1162-1164.

62. Roy L, Guilhot J, Martineau G, Larchée R, Guilhot F. Unexpected occurrence of second malignancies in patients treated with interferon followed by imatinib mesylate for chronic myelogenous leukemia. Leukemia. 2005;19:1689-1692.

63. Pilot PR, Sablinska K, Owen S, Hatfield A. Epidemiological analysis of second primary malignancies in more than 9500 patients treated with imatinib. Leukemia. 2006;20:148.

64. Cortes J, O'Dwyer ME. Clonal evolution in chronic myelogenous leukemia. Hematol Oncol Clin North Am. 2004;18:671-684.

65. Terre C, Eclache V, Rousselot P, et al. Report of 34 patients with clonal chromosomal abnormalities in Philadelphia-negative cells during imatinib treatment of Philadelphia-positive chronic myeloid leukemia. Leukemia. 2004;18:1340-1346.

66. Medina J, Kantarjian H, Talpaz M, et al. Chromosomal abnormalities in Philadelphia chromosome-negative metaphases appearing during imatinib mesylate therapy in patients with Philadelphia chromosomepositive chronic myelogenous leukemia in chronic phase. Cancer. 2003;98:1905-1911.

67. Kovitz C, Kantarjian H, Garcia-Manero G, Abruzzo LV, Cortes J. Myelodysplastic syndromes and acute leukemia developing after imatinib mesylate therapy for chronic myeloid leukemia. Blood. 2006;108:2811-2813.

68. Jabbour E, Kantarjian HM, Abruzzo LV, et al. Chromosomal abnormalities in Philadelphia chromosome negative metaphases appearing during imatinib mesylate therapy in patients with newly diagnosed chronic myeloid leukemia in chronic phase. Blood. 2007;110: 2991-2995.

69. Ebnöether M, Stentoft J, Ford J, Buhl L, Gratwohl A. Cerebral edema as a possible complication of treatment with imatinib. Lancet. 2002;359:1751-1752.

70. Goldman JM, Mughal TI. Chronic Myeloid Leukemia, Hoffbrand, Tuttenham, Catovsky, editors Oxford, UK: Blackwell Science; 2005.

71. Valsamis HA, et al. Antiepileptic drugs and bone metabolism. Nutr Metab. 2006;3:36. doi:10.1186/1743-7075-3-36.
Biologics: Targets \& Therapy

\section{Publish your work in this journal}

Biologics: Targets \& Therapy is an international, peer-reviewed journal focusing on the patho-physiological rationale for and clinical application of Biologic agents in the management of autoimmune diseases, cancers or other pathologies where a molecular target can be identified This journal is indexed on PubMed Central, CAS, EMBase, Scopus

\section{Dovepress}

and the Elsevier Bibliographic databases. The manuscript management system is completely online and includes a very quick and fair peerreview system, which is all easy to use. Visit http://www.dovepress. com/testimonials.php to read real quotes from published authors. 